\title{
Role of MRI in evaluation of small bowel disease
}

\author{
Foad Serag El-Dein, Khaled M Moghazy*, Amany El-banna, Ahmed Hafez Afifi, Abeer Abo-Ellela \\ From International Cancer Imaging Society Meeting and 15th Annual Teaching Course (ICIS 2015) \\ London, UK. 5-7 October 2015
}

\section{Introduction}

Magnetic Resonance Imaging of the Small Bowel (MR Enterography, or MRE) is becoming increasingly popular as the first imaging modality for the diagnosis and follow-up of small bowel diseases. The aim of this work was to evaluate the role of recent MRI sequences and techniques in evaluation of small bowel disease.

\section{Patients and methods}

The study population included 24 patients who were referred to multiple radiology centers by gastroenterologist for magnetic resonance enterography (MRE) for evaluation. The examination was done on 1.5 Tesla superconducting magnet MRI.

\section{Results}

All studied patients had small bowel lesions. 15 patients were neoplastic (64\%) and 9 patients were inflammatory (36\%). Among 15 cases of small-bowel neoplasm; 12 were malignant; and 3 were benign. The malignant cases were classified as follows; lymphoma (6 patients); adenocarcinoma (4 patients); GIST (1 patients) and carcinoid tumour (1 patient). Nine patients out of 24 had inflammatory bowel diseases. Eight cases out of 9 proved to be specific inflammatory disease and 1 chronic non specific ileocolitis. Seven cases out of 8 proved to be Crohn's disease and 1 proved pathologically to be TB of small bowel. The final diagnosis was confirmed by surgical or endoscopic data and follow up.

\section{Conclusions}

MRE is accurate non-invasive modalities in assessing the intra-luminal, parietal and extra-luminal small bowel tumour without the need for ionizing radiation. MR signal appearances of the lesions, combined with the contrast enhancement behavior and the characteristic of the

* Correspondence: moghazy20@yahoo.com

Radio-diagnosis Department, Alexandria University, Alexandria, Egypt stenosis, can help in differentiating neoplastic from other non-neoplastic diseases of small bowel.

Published: 2 October 2015

doi:10.1186/1470-7330-15-S1-P5

Cite this article as: El-Dein et al:: Role of MRI in evaluation of small bowel disease. Cancer Imaging 2015 15(Suppl 1):P5.
Submit your next manuscript to BioMed Central and take full advantage of:

- Convenient online submission

- Thorough peer review

- No space constraints or color figure charges

- Immediate publication on acceptance

- Inclusion in PubMed, CAS, Scopus and Google Scholar

- Research which is freely available for redistribution
() Biomed Central
C Biomed Central

(C) 2015 El-Dein et al. This is an Open Access article distributed under the terms of the Creative Commons Attribution License (http:// creativecommons.org/licenses/by/4.0), which permits unrestricted use, distribution, and reproduction in any medium, provided the original work is properly cited. The Creative Commons Public Domain Dedication waiver (http://creativecommons.org/publicdomain/ zero/1.0/) applies to the data made available in this article, unless otherwise stated. 